\title{
On Foreign Language Creation and Rootless Back Translation -A Case Study of Snow Flower and the Secret Fan*
}

\author{
GUO Ting \\ Guangdong University of Technology, Guangzhou, Guangdong Province, China
}

\begin{abstract}
With Adaptation Theory as its theoretical basis, this research makes comparison between Lisa See's original version of Snow Flower and the Secret Fan and Xin Yuanjie's Chinese translation based on a self-compiled manual annotation English-Chinese bilingual corpus. It aims at exploring the choice of language and the choice of translation method in the foreign language creation and rootless back-translation of Snow Flower and the Secret Fan, discussing whether these choices adapt to the source language or the target language, and finding out the communicative effects they have achieved. The preliminary results show that: the choice of language and the choice of translation method in Foreign Language Creation mainly adapt to the target language to make easier for the target English readers to understand and partly adapt to the source language to keep local flavor; the choice of language and the choice of translation method in rootless back translation mainly adapt to the target language to make the translation authentic, accurate and smooth, and adaption to source language will lead to translationese. This research sheds new light on this special kind of writing and translation.
\end{abstract}

Keywords: foreign language creation, rootless back translation, self-compiled corpora, choice of language, choice of translation method

\section{Introduction and Concepts}

As the development of globalization, the expansion of cultural exchanges, a new writing style appears-local cultural content described by foreign language, for example, Chinese events written in English language: Marco Polo's Travels and Red Star Over China.

According to the literature studied, the writing of Chinese events written in English language can be classified into three groups: (1) Chinese stories written in English by bilingual writers who are Chinese cultural background, for example, Lin Yutang's Peking in Moment; (2) Chinese stories written in English by native English writers, for example, Kissinger's On China; (3) Chinese stories written in English by American Chinese writers who are mixed cultural background, for example, Amy Tan's the Joy Luck Club. As to the types of writing, it includes travelogue, biography, essay, novels, reports, academic writings and so on.

This foreign language creation is usually popular among English readers and the writers usually have good command of English language and transfer Chinese culture well, so it is meaningful to study from a linguistic

\footnotetext{
* This paper is funded by China National Social Science Fund Youth Project "Studies on Foreign Language Creation and Rootless Back Translation Based on Corpus” (2016CYY010).

GUO Ting, Master’s Degree of literature, Lecturer, Department of Art and Design, Guangdong University of Technology.
} 
angle how English expresses Chinese culture, and why it is accepted by target readers. Its research findings contribute to enhancing the linguistic strategies of Chinese culture spreading. This research will help to enhance English expressive ability greatly and spread Chinese culture effectively, and it will help us to understand Chinese culture in a different and exotic angle, restore history and find the lost cultural treasures, besides it will help us to find the misunderstanding in delivering Chinese culture. For this creation of Chinese events written in English language, when it is translated back into Chinese, it seems easy but difficult to have quality translation.This back translation contributes to retrieving lost or forgotten historical materials and enrich Chinese culture. And furthermore, the research results shed new light on other foreign language creation and rootless back translation, for example, English discourse of Japanese events, French novel of Indian culture and so on. Now the publishing and translation of this creation increase gradually, the research of this writing and its back translation has become an academic hot point.

Wang Hongyin put forward the academic terms "foreign language creation" and "rootless back translation” in 2009. "Foreign language creation” refers to a novel of Chinese culture written in English, and its Chinese translation belongs to "rootless back translation", that is, back translation of English version into the non-existent Chinese "original version", among it the restoration of some quotations to the original text is called "original text restoration”. The academic terms "foreign language creation”, "rootless back translation" and "original text restoration" are employed as the basis of academic terms.

On the basis of large amount of data materials, it is discovered that foreign language creation involves narration or comment writing and invisible translation in transferring Chinese culture. The writers make adaptation, translation or fabrication in narrative and commenting writing part, and translate the Chinese culture into English by various methods.

To assist the research, a self-compiled corpus is employed and manual annotation is adopted. The language materials are originated from Lisa See's novel Snow Flower and the Secret Fan. Lisa See is a native writer and her novel is about China.

\section{Theoretical Framework and Research Methodology}

This research studies from a linguistic and pragmatic angle. The core idea of Verschueren's Adaptation is that language using means making continuous choices in linguistic context and communicative context. "Language choice-making is a process of adaptation to variable possibilities on the negotiation made by the communicators” (Verschueren, 2000, pp. 59-61). According to Adaptation Theory, choice-making can occur at any level of linguistic forms varying from phonics, tones, lexicon, sentence to text; language users choose forms as well as strategies when making choices; choice-making is involved both in the production and interpretation of an utterance (Verschueren, 2000, pp. 56-58). Writing and translation is a process of language using, a process of making choices linguistically and strategically.

Under the theoretic framework of Adaptation Theory, the choice of language and the choice of translation method will be conducted in this research. And the data of the self-compiled English and Chinese parallel corpus will be annotated manually according to this classification.

Here the research questions are put forward as follows: 
Question 1: How does English express Chinese events in Foreign Language Creation? Why are these foreign language creations accepted by English readers? What is the choice of language? And what is the choice of translation method? What communicative effects are achieved?

Question 2: In rootless back translation, what is the choice of language and what is the choice of translation method to reconstruct Chinese culture? What communicative effects are achieved?

\section{Analysis on the Foreign Language Creation}

Linguistically, the writer of Snow Flower and the Secret Fan makes choice at the level of phonics, lexicon, syntax, discourse, and strategically, the writer makes choice in various translation methods.

\section{Choice of Language}

At the level of phonics, Snow Flower and the Secret Fan borrowed a lot of Chinese Pinyin, such as fengshui, chi, yin, yang and so on to adapt to the source language, so as to make the novel full of exotic flavor and satisfy the target reader's demand of seeking for difference and understanding the original and authentic Chinese culture; sometimes attached with explanation for these terms to adapt to the target language, so as to make it easier for the target readers to understand. On the other hand, the unique English phonetics appears to explain the unique cultural phenomena that exist in China only. For instance,

Example (1) So while a character might make a sound that creates the words for "pare", "pair”, or "pear", context usually makes the meaning clear.

The use of English homonyms "pare”, "pair”, or "pear", vividly explains that the "nushu" character is a phonetic or alphabetic writing. The choice of English homonyms but not Chinese homonyms is an adaptation to the target language. This choice may arouse the resonance of the target reader and make difficult and abstract concept easy to understand.

At the level of lexicon, elaborate diction of visualized words is employed. To make the exotic story become attracted and accepted by the target readers, the author makes very good use of the visualized words and expressions. For instance,

Example (2) To cement the relationship, their fathers had each contributed twenty-five jin of rice, which was stored at our house.

Example (3) My mother's eyes zeroed in on me. "Move! Progress is finally being made!”

Here, cement and zeroed are chosen in stead of consolidate and round-eyed, for this visualized expressions are precise, concrete, vivid and adding a crucial touch in telling the story. Besides, even the chapter titles in the novel are visualized words, such as Milk Years is used to refer to childhood, and rice-and-salt days is used to refer to after-married life. These visualized words can quickly grasp the readers' eyeball and form an image or picture in the mind, so the readers' interest is aroused.

In regard of syntactical context, the novel displays a masterly and spontaneous command of figure of speech. Some are borrowed from Chinese traditional culture, for example,

Example (4) I was a pearl in my father's palm.

Here, "a pearl in one's palm" is chosen instead of “an apple in one's eye”, it is an adaptation to the Chinese language, and it introduces Chinese culture and enriches English language. 
Alliteration, as one of English phonetic rhetoric device, shows the beauty of rhyme and symmetry, and this adaptation to the English language has strong expressive force and power. For example,

Example (5) He hemmed and hawed.

Generally speaking, the linguistic choices in phonetic, lexical, syntactic and textual context reflect a hybrid and blending feature of this creation. The choice of Chinese pinyin, Chinese figure of speech and literal translated expressions is adaptation to the source language; and the choice of English unique homonyms, visualized words and alliteration is adaptation to the target language.

From the above analysis, it is obvious that Lisa's writing process involves a translating process. While different from the traditional translation phenomenon, Lisa's translation and creation are interrelated with each other during her whole creating process.

Though from the surface, it appears that Lisa is just dealing with one language: English, in fact, considering from the perspective of her thinking activity and writing pattern, we can easily come to a conclusion that her writing mostly deals with an invisible translating activity which provides her researchers a good subject to approach to the translating activity.

\section{Choice of Translation Method}

Due to cultural differences between the two languages, many Chinese words and expressions do not have equivalents in English. In this novel, Lisa tried to introduce Chinese culture in the English language, so she actually translated some Chinese culture-loaded words or culturally indigenous concepts in his writing process. Five categories of cultural translation methods are chosen:

(1) Literal Translation

Transliteration means "writing a word, name, sentence, etc. in the alphabet of a different language or writing system” (Longman Dictionary of Contemporary English, 2004). Transliteration means translating an item according to its pronunciation rather than its meaning. Since there is no one-to-one correspondence in source language and target language, we can create one by adopting transliteration words in order to maintain their particular culture flavor. For instance:

Example (6) This can be explained by yin and yang: There are women and men, dark and light, sorrow and happiness. These things create balance.

In this example, through the opposite items "women and men, dark and light, sorrow and happiness" and the explanation of "These things create balance", the target readers can get the idea of yin and yang. However, when the target readers are familiar with the meaning of the lexemes, or it is not the first time to appear in the text, it is qualified for the translator to omit the explanation by using the transliteration only.

(2) Literal Translation

"Literal translation, also called word-for-word translation by Cicero (106-46 BC), Horace (65-8 BC) and virtually everyone thereafter, and meta-phases by JohnDryden (1631-1700), is ideally the segmentation of the SL text into individual wordsand TL rendering of those word-segments one at a time” (Mona Baker, 2004, p. 125). A literal translation is keenly oriented towards the source language structure, which exerts strong influence on determining accuracy and correctness. It can best preserve the cultural elements and national characteristics of the source language. This method is widely used in the novel and the examples are abundant. Usually, explanation words are added to provide background for the target reader to understand. In particular, 
in explaining some social customs, explanation may be added to show the symbolization meaning of the custom. For instance,

Example (7) Red eggs—a symbol of life dyed red for celebration—were given to the guests and relatives.

"Red eggs" is literal translation, "a symbol of life dyed red for celebration" is explanation, the literal translation plus explanation can be viewed as the translator's attempt to expand the context or the cognitive environment for the target reader to produce a roughly equivalent effect on the target reader as the source text on the source reader.

(3) Free Translation

According to Liu Chongde, free translation is "a supplementary means to mainly convey the meaning and spirit of the original without trying to reproduce its sentence patterns or figures of speech. And it is adopted only when and where it is really impossible for translators to do literal translation” (Liu Chongde, 1991, p. 53). Free translation refers to the translation of symbolic significance of Chinese origin concept rather than its literal meaning (Ge Lingling, 2011, pp. 117-122). Thus, compared with transliteration and literal translation which show great respect to the source language, free translation emphasizes the target language. The following example shows us the translation of the traditional Chinese wedding customs:

Example (8) But the moment passed, and we moved on to Teasing and Getting Loud in the Wedding Chamber. My husband's friends burst in, unsteady on their feet and feeble in their words from too much drink. They gave us peanuts and dates so we would have many children. They gave us sweets so we would have a sweet life.

From the above example, in free translation of some particular customs, the capitalized words are adopted to refer to a specific custom in a particular culture. In addition, with the help of explanative narration, the target reader can better understand the customs.

(4) Substitution

Substitution refers to "replace the original concept of Chinese culture of source language with the original concept of English used in the culture of target language" (Ge Lingling, 2011, pp. 117-122). Sometimes when the equivalent expressions can be found in the target language, substitution is usually used. Chinese addresses are difficult to be translated, so the unique English addresses "Madame”, "Master”, "Lady”, "Miss”, are chosen to refer to “太太”, “老爷”, “夫人”, “小姐”, to shorten the distance of cognition.

(5) Integrated Translation

The integrated translation refers to combination of more than two kinds of the above 4 kinds of the most basic source concept translation mode (Ge Lingling, 2011, pp. 117-122). The integration of transliteration and literal translation is used in translating some place names or some abstract concepts, for instance:

Example (9) Yongming County, the county of Everlasting Brightness

In the above examples, both the pinyin forms (Yongming), and the language forms (Everlasting Brightness) are translated into English to keep its original flavor. The combination of transliteration and free translation is used in translating some difficult philosophy concepts or customs or unique cultural items. Such as Jinshi scholar, "jinshi" is actually a kind of scholar. Therefore, the integration of transliteration and free translation is used to make the meaning of this culture terms clear to the target English reader with consideration of their curiosity for foreignness. This translation method bridges the distance between the source text and the target 
reader while maintaining the cultural flavor to a large extent.The integration of literal translation and free translation is a common way to translate the form and the content of some idioms and proverbs, for instance,

Example (10) I was precious to him. For the moment, I was like a pearl in his hand.

The writer used "a pearl in his hand" instead of "an apple in one's eye" to make the readers understand the Chinese expression better, the writer also explains it through "I was precious to him". The choice of "integration" makes the items full of exotic flavor and makes them easy to be understood by the target English reader. And it is an adaptation to both the source language and the target language, which shortens the distance between the source language and the target language and promotes cultural transmission.

In summary, the writer chooses various kinds of language forms and translation methods to adapt to the source language to keep the local favor, while adapting to the target language to make the text easy to understand.

\section{Analysis on Textless Back Translation}

The rootless back translation, the translation of the English foreign language creation into Chinese seems easy, however, it has its difficulties, because the Chinese readers are familiar with Chinese culture, and the translation is easy to be translationese.

In Xin Yuanjie's Chinese rootless back translation, to better restore the Chinese culture, linguistically, four-character phrase, concrete words and culturally indigenous concepts expression to express original culture; strategically, substitution, omission, free translation, amplification, literal translation are chosen to better restore or reproduce the original culture.

\section{Choice of Language}

(1) Four Character Phrase

The Chinese language values symmetry and frequently uses four-character phrases. The translator transforms the loose sentence structure of English into four-character phrases, which conform to the habit of the Chinese language. For example,

Example (11) The home of a learned official.

\section{饱读诗书的官宦之家}

Example (12) You know the old saying about beautiful people marrying beautiful people and talented people marrying talented people?

古人说郎才女貌、才子佳人、如花美滕、一对璧人什么的

From these examples, the translation of four-character phrases makes the text so balanced and symmetrical that strike reader's feelings. It is simple in form but strong in passion. The usage of four-character phrases can be seen everywhere in the Chinese version. This adoption of four-character phrases is adaptation to the target language.

\section{(2) Concrete Word}

Concrete word is also a distinct feature of the translation text. To make abstract words concrete can smooth the Chinese readers' reading and reduce the reading barriers and deepen the understanding. The examples found in the translation are as follows:

Example (13) We all wish to be born well and marry well; we all wish to die well and be buried well. 


\section{我们都想生得富有, 嫁得体面, 死得安逸, 葬得隆重}

In this example, the translator uses concrete words to make the meaning of "well” clear, in different situations, the word "well" has different meanings, so specific meanings should be explored. Another example,

Example (14) In that moment I changed from being invisible to being very visible.

$$
\text { 那一刻的我一下子从透明人变成众人的焦点 }
$$

In above example, "invisible" and "visible" are abstract words and its Chinese corresponding words are concrete. Such transparent and fluent translations evoke resonance among the Chinese readers, reduce the distance between the source text and the target reader and reduce the psychological pressure in understanding. This adjustment is also adaptation to the target language. Therefore, it is necessary to realize the different characteristics of Chinese and English language, and make corresponding adaptation. All these efforts are made to adapt to the Chinese readers, and have the effect of shortening the psychological distance and reduce the reading barriers, so that the translation can be accepted by Chinese readers.

(3) Culturally Indigenous Concept Expression

In the act of back translation, the translator adopts a lot of culturally indigenous concept expressions to make the language full of local favor, and seems natural and real. For instance,

Example (15) In the hottest day in the summer.

$$
\text { 正值三伏天 }
$$

Example (16) Two matchmakers were at each other's throats from then on.

$$
\text { 两个媒婆间便水火不容 }
$$

In the Example (15), in Chinese culture, “三伏天”, refers to the days between slight heat and great heat, the year of the highest temperature and humid, sultry days. This translation adapts to the target Chinese culture, and makes it acceptable to the Chinese readers.

In the Example (16), "at each other's throats" is an English idiom, while translating into Chinese; the translator substituted it with a Chinese idiom. This domestication expression is an embodiment of adapting to the Chinese language. Here are more examples:

Example (17) Snow Flower's family didn’t feel I was her equal.

$$
\text { 雪花的家人认为我们之间门不当户不对 }
$$

Culturally indigenous concept expression makes great contribution to keep away from the translationese and makes the translation authentic and smooth. Culturally indigenous concept expression or culture-loaded words that in accordance with the Chinese cultural characteristics, with the characteristics of the times, stylistic features, with specific content and in line with the identity and personality of the characters will be accepted by the modern Chinese readers. In the rootless back translation, culturally indigenous concept expression is widely used to adapt to target Chinese language.

\section{Choice of Translation Method}

When doing the rootless back translation, the translator should consider the question: what translation method is used to reproduce the original culture in its original language completely and effectively, and make the Chinese readers, who are familiar with Chinese culture, feel the translation is native and smooth and acceptable.

(1) Substitution 
This method means replacing a source language word or expression with a target language item that has a different propositional meaning but is likely to have a similar pragmatic impact on the target reader (Zhao Hongjian, 2004, p. 45). When writing Snow Flower and the Secret Fan, Lisa quotes some Chinese classics such as poems and proverbs by translating them into English. Now in English-Chinese translation of this novel, the translator needs to trace the original sources of these poems and proverbs and uses them directly in his translation. He should not make any changes or adaptations, because all the poems and proverbs are very famous ones, which all Chinese people are familiar with. If he invents his own version, the Chinese readers will not be able to match the new version with his memory and will not accept it. Also for some cultural specific expressions, although Lisa adopts various ways to translate them into Chinese, the translator should back-translate them accurately into Chinese. Otherwise, he will make mistakes and cannot meet the requirements of Chinese readers. Here are some examples:

Example (18) "The bed is lit by moon light.

I think it is the light snow of an early winter morning.

Looking up, I enjoy the full moon in the night sky.

Bending over, I miss my hometown.”

Example (19) Read a thousand books, and your words will flow like a river.

读书破万卷, 下笔如有神

In Example (18) “静夜思” (On a Quiet Night) is a well-known ancient poem and the poem is familiar to Chinese readers, although free translation is applied in Lisa's translation, it already has fixed Chinese poem version. As to Example (19), the writer may employ flexible ways to translate idioms and proverbs, but the Chinese idioms and proverbs are established by usage. What the translator should do is to make efforts to find out or trace back the exact or original poem, remarks and quotations and then use them directly, so as to make his translation accurate. From the above examples, when it comes to the transliteration word, book names, proverbs, poems, classics and so on, "substitution”or “original text restoration” should be used. Besides, for those expressions that can find Chinese culture-loaded words to take place of, "substitution" is adopted. This is adaptation to the target language.

(2) Omission

Sometimes if the translator cannot find an appropriate way of conveying the original meaning, omission will be adopted. It is to conform to usage as well as rhetoric characteristics of the target language (Lv Ruichang \& Yu Yungen, 1983, p. 16). Omission means some words on the original texts are not translated into the target text because the translation has its meaning though without the word, or the meaning is self-evident in the translation. In other words, omission means deleting some words not essential or is too cumbersome or contrary to the habits of the target language, but omission does not mean deleting some original ideological content (Zhang Peiji, 2000, p. 88).

Lisa describes the daily life of Chinese families and the relationships in great details, but the target reader is the common English reader, therefore, the author will inevitably increase the explanatory language of individual words in writing, with the aim of spreading the foreign and exotic culture to English readers. In other words, to make the abstract concrete, the complicated simplified, Lisa sometimes added extra explanations or vivid details to make English readers better and deepen the understanding the Chinese culture. While in the act 
of translating it back into Chinese, omission is put to use because the Chinese readers are very familiar with it. Because too much explanation words make the text miscellaneous and trivial, and may affect the Chinese readers' smooth reading, so some specific details would be deleted. There are some cultural factors, the Anglo-American readers cannot understand without explanation, but to Chinese readers, the explanations are just like "carry coals to Newcastle", completely superfluous. Thus, to remove the superfluous information will be reasonable. For example,

Example (20) Jinshi scholar.

进士

Here, “scholar” is left out. This omission will not affect Chinese readers' understanding of “进士”, but make it concise and clear. Another example,

Example (21) Hyacinth bean and papayas, long vines, deep roots. Palm trees inside the garden walls, with deep roots, stand a thousand years.

永结连理, 亘古不变

The translator uses free translation, "Hyacinth bean and papayas, long vines," "Palm trees inside the garden walls," are all left out, because these details are difficult and unnecessary for Chinese readers to understand, so the translator just tells the key information and deletes the trivial details. For some misunderstanding for Chinese culture, in the translation, omission is also adopted.

(3) Free Translation

Besides omission, free translation is usually adopted to adapt to different situation. Free translation reproduces the matter without the manner or the content without the form of the original (Peter Newmark, 2001, p. 46). Sometimes, if the translator found the original has deviation in understanding of the national culture, he would consciously make adjustments to the translation. Owing to the content is concerning about the translator's native language and culture, the translator has more right to speak in the truthfulness and accuracy of the original information. If the information is wrong or inappropriate, in order to take the reader's cognitive harmony into account and adapt to the target culture, the translator probably will take the initiative to adjust the content, even without explanation. The following is an example,

Example (22) "The fibers between us are connected even if the lotus root is cut" 我们虽生死相隔, 但心心相系啊

In Chinese, the English sentence means “藕断丝连”, suggesting the relationship is cut in appearance, in fact they still have connections, and it is used usually between lovers. In the text, the writer uses this expression to refer to the friendship of grandma and her sworn sisters, and the sworn sisters chant these to remember the dead grandma. Here it refers to the friendship, so some adjustment is made, and free translation is used to adapt to the situational language and culture context.

(4) Amplification

Amplification means adding one or more words which does or do not exist in the source item (Yu Yungen, 1983, p. 16). This method can remove the cultural obstacles by the direct explanation within the text so that the target reader can read the translation fluently and the interests can be maintained. Sometimes the translator also adopts amplification to add local favor, because the translator is too familiar with it.

Example (23) She was no match for palace intrigues. 


\section{可怜的雨秀在后宫的明争暗斗中根本不是那些贵妃才人们的对手}

In the above example, when encountering the topic or field that is especially familiar with, the translator will unconsciously mobilize the relevant native culture cognition, and add some information that does not exist in the original during the output stage of translation, so that the translation may seem more natural and smooth, and it is easier for the readers to accept the translation.

(5) Literal Translation

Literal translation refers to the translation of Chinese source language forms of a source concept into English language forms to make the target reader understood (Ge Lingling, 2011, pp. 117-122). In the Chinese back translation, literal translation is also widely adopted, for example,

Example (24) Snow Flower 雪花

Literal translation helps to return to the original version, but also it can cause translationese, for example,

Example (25) "the one who yet not die"—a widow, eighty years old. “唯一还未死去的人”

In Chinese there is a fixed expression to “the one who yet not die”: “未亡人”, but here the translator does not trace back the origin of this quotation word because of knowledge limitation, and adopts literal translation, as a result, the translation is full of tranlationese, and the Chinese reader is puzzled for this poor expression. So this is the difficulty in back translation. To avoid tranlationese, the translator has to try best to make choice of language and translation method to adapt to the target language.

\section{Major Findings and Implications}

Under the Adaptation Theory, the process of foreign language creation and rootless back translation is a process of making choices. This research adopts a self-compiled corpus to gather language materials and attempts to find out what choice of language and choice of translation method are made in the foreign language creation and rootless back translation of Snow Flower and the Secret Fan, and explores whether these language choices adapt to the source language or the target language. According to the research result, in foreign language creation, the writer chooses language form of transliterate word, visualized word and figurative speech, and translation method of transliteration, literal translation, free translation, substitution and integration to narrate, convey and express exotic Chinese culture.These choices adapt to the source language to keep the local favor, while adapting to the target language to make the text easy to understand. In rootless back translation, language form of four-word phrase, culturally indigenous concept expression and concrete word and translation method of substitution, omission, free translation and amplification are chosen to reproduce or restore the Chinese culture. These choices mainly adapt to the target language to make the translation authentic, accurate and smooth, while occasionally adapt to the source language will lead to translationnese, inaccurate and unnatural.

\section{Conclusion}

Foreign language creation as a cross-cultural and cross-language choice-making process, is a good example of English writing and English expressiveness of Chinese culture. While rootless back translation as a intercultural and cross language choice making process,help us understand the difference between two 
languages and restore lost cultural materials. The research on this case study of Snow Flower and Secret Fan is a typical Chinese story written in English by native English writers. There is an old saying in Chinese "to look at one spot on leopard and you can visualize the whole animal, to conjure up the whole thing through seeing part of it.” The research of this case study adopts a linguistic way to analyze its writing and back translation, and research results come from a large amount of corpus data analysis and comparison. The choices of language and translation method would be employed in this special writing and translation and the research findings could be served as a guide,so the research result sheds new light on the same kind of foreign language creation and rootless back translation.

\section{References}

Baker, M. (2004). Routledge encyclopedia of translation studies (p. 125). Shanghai: Shanghai Foreign Language Education Press.

GE, L. L. (2002). Revelation of adaptation theory to translation studies-Also on pragmatic translation criteria. Foreign Language Research, (3), 7-11.

GE, L. L. (2011). On the patterns for translating alien sources in humorous texts—A study based on a Chinese-English bilingual parallel corpus. Foreign Language Research, (1), 117-122.

GUO, T., \& GE, L. L. (2014). On rootless back-translation based on an English-Chinese bilingual corpus. Foreign Language Research, (6), 95-98.

HE, Y. J. (2004). Mapping culturally indigenous concepts in the translation process: A cognitive perspective. Journal of Translation Studies, (9), 33-50.

HE, Y. J. (2010). On translating alien sources: Its patterns and cognition. Foreign Language Teaching and Research, (3), 211.

HU, G. S. (2003). Translation as adaptation and selection. Perspectives: Studies in Translation Theory and Practice, (11).

LIU, C. D. (1998). Ten lectures on literary translation. Beijing: China Translation and Publishing Corporation.

Longman Dictionary of Contemporary English. (2004). Beingjing: The Commercial Press.Longman Dictionary of Contemporary English. (2004). 北京: 商务印书馆.

LV, R. C., \& YU, Y. G. (1983) A Chinese to English translation course. Xi'an: Shanxi People’s Press.

Newmark, P. A. (2001). Textbook of translation (p. 46). Shanghai: Shanghai Foreign Language Education Press.

Nida, E. A. (2001). Language, culture and translation. Shanghai: Shanghai Foreign Language Education Press.

See, L. (2005). Snow FLower and the Secret Fan. New York: Random House.

Shuttleworth, M. \& Moira, M. (2004). Dictionary of translation studies. Shanghai: Shanghai Foreign Language Education Press.

Verschueren, J. (2000). Understanding pragmatics. Beijing: Foreign Language Publishing House.

WANG, H. Y., \& JIANG, H. M. (2012). Foreign language creation and rootless back translation of Moment in Peking. Foreign Languages and Their Teaching, (2), 68-72.

XIN, Y. J. (2006). Snow Flower and the Secret Fan (Chinese Version). Beijing: People's Literature Publishing House.

ZHANG, P. J. (2000). An English to Chinese translation course (pp. 58-88). Shanghai: Shanghai Foreign Teaching Publishing House. 